\title{
The Influence of Social Taboos on Socialization of Students: Evidence from a Developing Country
}

\author{
lqbal Ahmad \\ Universiti Teknologi Malaysia \\ shahnavi777@hotmail.com \\ Hamdan Said \\ Universiti Teknologi Malaysia \\ p-hamdan@utm.my \\ Syed Shafeq Syed Mansor \\ Universiti Teknologi Malaysia \\ p-shafeq@utm.my
}

Doi:10.5901/mjss.2015.v6n2p514

\begin{abstract}
There is evidence that students in Pakistani schools face many problems due to rigid social structure and strict formalisation of roles and rules. This situation is broadly supported by the social norm which compels students to compromise on their broad social development and thus many students lose their individual identity or freedom. This paper examines the effect of social taboos on socialization of students at secondary school level in Pakistan. Previous literature on the effects of social taboos on socialization of students in Pakistani society is scanty. This paper contributes to existing literature by inquiring the perceptions of teachers about the influence of two dimensions of social development: specific socialization and general socialization of students. For data collection, a self-created survey questionnaire was administered to 300 randomly selected secondary school teachers from district Malakand, Khyber Pakhtunkhwa, Pakistan. For data analysis, linear regression analysis was employed. Findings of the study revealed a significant negative correlation between social taboos and socialization of students and its two dimensions: specific socialisation and general socialisation. On the basis of the results, the study concludes that social taboos are negative predictors of socialization of students.
\end{abstract}

Keywords: social taboos, socialization, specific socialization, general socialization

\section{Introduction}

Human behaviour is governed by many social factors such as affiliations, norms, practices, beliefs and actions (Strong, 2005). Societies have often shared values and standards which are recognized as acceptable norms for the members of the society to practice (Zia, 2012). A society or culture basically guides the behaviour of the individuals through these norms and practices. Social taboos are specific beliefs of people about various dimensions of life (Colding \& Folke, 2001). These beliefs are developed over many years and provide strong guidelines to the people to adopt or avoid certain habits or practices in a particular society. Social taboos have a deeper effect on social development of people. People behave, dress, eat and pattern their lives according to the prevailing social norms. Actually social norms are the driving forces behind the functioning of societies and individuals (Fehr \& Fischbacher, 2004).

Social norms play a key role in developing the patterns of human personality and behaviour called socialization or humanization (Young, 2011). Socialization is a process of development of individuals in which they come in contact with other members of the society, practices and beliefs. This interaction forms the foundation of the ideology or social temperament of the individuals which in turn plays a vital role in the development of personality of a person. There is a close relationship between social norms and socialization (Fershtmen, Gneezy, \& Hoffman, 2011). Almost in very society of the world social taboos exist. However, it is believed in Pakistani society the prevalence of social taboos have deeply affected the academic development of students. The social taboos exist in the form of jargons, terms, euphemisms and different metaphoric expressions. Over the years, this phenomenon has led to discussions and confusions among the 
researchers and scholars regarding the effect of the social taboos in relation to social development of Pakistani youth vis a vis the rapidly changing global scenarios (Hussain \& Khan, 2008).

An extensive literature is available on social norms and taboos in different societies around the world. However, anthropologists have documented and analyzed the taboos in various ways. The term taboo basically is a Polynesian origin and is taken from the words 'tabu' or 'tapu' in Tongan language. It was introduced to English language in eighteen century. According to Encyclopaedia Britannica, taboos are the prohibition of some action on the basis of a belief that such behaviour may be dangerous and accursed for ordinary individuals to undertake. Taboo is a prohibition of certain social action which may cause violation of some norms commonly held by all in the society or which may call the wrath of a supernatural punishment believed by members of the society (Jejeebhoy, Shah, \& Puri, 2003). Broadly speaking, it is based on a belief that such behaviour is a scared or accursed for others in the society to practice. Such types of social prohibitions are present in human society since time immemorial. In some societies, such prohibitions are related to an area of human activity or a custom which is sacred or forbidden or deemed objectionable by the society in general (Fiske \& Tetlock, 1997). Studies have revealed that social taboos undergo changes overtime. Some taboos may disappear and other may become stronger or even dominate the prevailing customs of the society (Hari, 2002). For example, life insurance and child insurance remained taboos for a long time in some societies around the world and became acceptable in later periods (McCauley, Salter, Kiragu, \& Senderowitz, 1995). In some societies, trading human organs is treated as a taboo and is strictly prohibited. However, in recent times, some parts of human body have become acceptable. There are even some claims that famous incest taboos are fast disappearing in some complex societies around the world (Zia, 2012).

There are numerous explanations for the origin of social taboos. Anthropologists argue that the origin of taboos is culturally rooted. The alternative argument is held by psychoanalysts. They place emphasis on the role of strong subconscious prohibitions that pass through generations and constitute taboos (Al-Khatib, 1995). General socialization is the broad orientation of an individual with the overall norms and principles in the society in relation to other societies. On the other hand, specific socialization is the specific orientation of an individual with the norms and practices in a particular society (Young, 2011). Social taboos are strong social norms that are viewed as sacred by some societies (Durrant, 2000). However, in other societies, when behaviour of an individual is diverted from a particular norm, it is taken as violation of a social norm or taboo by other members of the society and may lead to punishment for the deviation. This act of deviation or prohibition impacts the social development of an individual. When the behaviour of an individual diverges or deviates from a social norm it has its effect on other members of the society (Ahmad, Ghani, Alam, \& Gul, 2013).

Although social taboos are considered as essential elements of social identity, there are severe social sanctions behind taboos. These are enforced by social punishment techniques (Uzma, 2008). Some of the most famous social punishments are reaction by other members of the society which may lead to social isolation or social banishment of the violator. This social reclusion as a result of the social repulsion leads to depression and social isolation on the part of some individuals (Young, 2008). Consequently, this causes the appearance of disgruntled elements which may lead to social chaos in a society (Benabou \& Tirole, 2004). Some writers say that social taboos are an important part of social identity. The identity part includes association with certain norms which characterizes the whole personality of an individual. Identification is an important element of socialization. The desire to maintain an identity is defined by the association with certain social norms prevailing in the society. This desire shapes the social development of an individual (Bott \& Jejeebhoy, 2001).

As mentioned above, some social taboos are prohibited by law and religious sanctions and their transgression may lead to severe punishment, for example, trading in human organs, dealing in pornography, underage sex and so on (Qanbar, 2011). Generally speaking, in every society of the world, there are three types of incentives that govern human behaviour such as monetary incentives, social incentives and legal incentives. The basic purpose of these is to prohibit behaviours from violation of the social norms. In some societies, social taboos create barriers for social interaction among people. The power of a taboo is influenced by the percentage of individuals who deviate or violate the social norm or even thinking of deviation (Fessler \& Navarrette, 2003). The sensitivity of social taboo varies from society to society and culture to culture. Social taboos also exist in Pakistani society. A study report has indicated that Pakistan has the largest cohort of young people, that is, 25 million between 15 to 25 ages (Government of Pakistan, 2001). Research on adolescents in Pakistan related to their socialization is still a new topic for researchers. Social taboos restrict the open discussion on sexuality or other related issues. There is a dearth of research on social taboos in Pakistan (Khan, 2000; Ali, Ali, Waheed, \& Memon, 2006).

Interestingly, in Pakistan social taboos are protected by cultural, religious sanctions and legal procedures as well as social norms and values (Khan, 1998; Khan, 2000). Another example is that unmarried girls are put in reclusion (Purdah) from puberty onward (Bott \& Jejeebhoy, 2001; Khan, 2000). In Pakistan, there exists no formal curriculum in 
school for sex education (Khan, 2000). Hence, due to family social taboos, many adolescents in Pakistan are poorly informed about sexuality, marital life, sexual issues, reproductive biology, low level of school attendance, lack of sex education and health. All these exacerbate and confound ignorance on these matters (Khan, 2000).

Earlier, a study on taboos conducted in China found various forms of taboos such as quasi-taboo and non-taboo, sex and anti-religion (Xiaogin, 2001). Another study conducted by Al-Khatib (1995) in Jordan on linguistic taboos indicated that socio-cultural factors determine the words used during conversation which are allowed and vice-versa. Mbaya (2002) studied social norms and customs in Oromo culture in Ethiopia. The study found it was prohibited in that culture to mention names for husbands, wife and certain in-laws. Instead, they use substitute words full of beauty and respect in place of the real names. In another study, Seifried (2006) found that American society observes some categories of verbal taboos such sex and bodily functions. The existence of social taboos is present almost in all societies of the world. In Yemeni society, a person who violates the basic family norms and respect for elders is subjected to sanctions of law (Khan, 2000). Whether a taboo should be used or what should be the degree of its acceptance or prohibition depends on socio-cultural, religious factors which are deeply rooted in that society (Holmes, 1992).

\section{Research Framework}

On the basis of the literature review, the researchers developed the following research framework for testing. The framework shows a linear direction of relationship between the independent variable (social taboos) and dependent variables (Socialization and its two dimensions: general socialization and specific socialization).

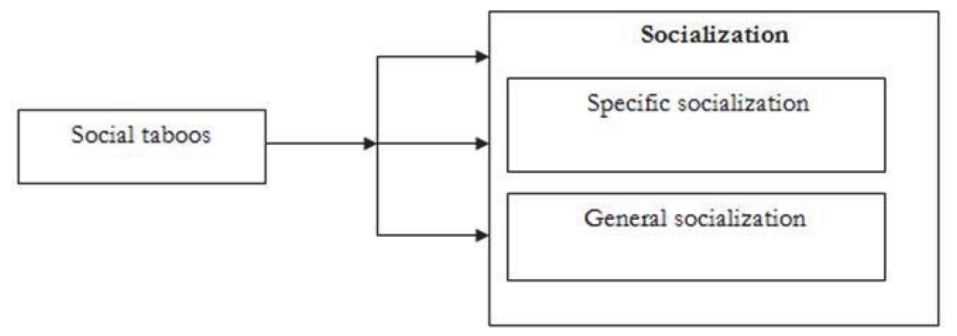

\section{Methodology}

\section{Research objectives}

- To examine the effect of social taboos on socialization of students at secondary school level in Pakistan.

- To examine the effect of social taboos on general socialization of students at secondary school level in Pakistan.

- Examine the effect of social taboos on specific socialization of students at secondary school level in Pakistan. Research questions

- Is there a relationship between social taboos and socialization of students?

- Is there a relationship between social taboos and general socialization of students?

- Is there a relationship between social taboos and specific socialization of students? Hypothesis

- There is a relationship between social taboos and socialization of students.

- There is a relationship between social taboos and general socialization of students.

- There is a relationship between social taboos and specific socialization of students.

Research instrument

This study uses a correlation design. This design is popularly used in relationship studies. This design suites this research study as well. In correlation studies, the direction and strength of relationship between one or more than one variables is examined (Gay, Mills \& Airasian, 2009). A cross-sectional method was used for data collection. This method is used to collect data faster (Cohen, Manion \& Morrison, 2007). For this study, this method of data collection was used due to shortage of time and resources. The study randomly sampled 300 secondary school teachers from a population of 7300 teachers on the basis of Krejcie and Morgan (1970) method. The data was collected from 30 schools of Malakand district Khyber Pakhtunkhwa, Pakistan. Random sampling was used to reduce the chances of sampling error and increase the degree of equal representation for generalization of the findings (Best \& Kahn, 2005). A self-designed 
questionnaire consisting of 15 items were used for data collection. The researchers personally administered the questionnaire to the respondents. The reliability of the instrument was checked using internal consistency using Cronbach's alpha reliability technique. The alpha value of the scale was found to be 0.78 that is acceptable level for using a scale for data collection. The validity of the scale was censured by systematic literature review and showing the scale to two experts. The scale items were designed on Five Point Likert Scale ranging from strongly disagree (value =1) to strongly agree (value =5). Statistical software SPSS was used to analyze the data. To see the relationship between the independent and dependent variables, linear regression analysis was employed.

\section{Research Finding}

Correlation analysis

Correlation analysis was conducted to examine the relationship between independent variable (social taboos) and dependent variables (socialization and its two dimensions: general socialization and specific socialization) of students.

Table 1. Correlation analysis of social taboos and socialization of students

\begin{tabular}{|l|c|c|c|c|}
\hline Variables & Socialization & General socialization & Specific socialization & Social Taboos \\
\hline Socialization & 1 & & & \\
\hline General socialization & $0.712^{\star}$ & 1 & & \\
\hline Specific socialization & $0.651^{*}$ & $0.732^{\star}$ & 1 & \\
\hline Social Taboos & $0.623^{*}$ & 0.593 & 0.722 & 1 \\
\hline
\end{tabular}

${ }^{*}$ Correlation is significant at the 0.01 level (2-tailed).

Table 1 shows that social taboos are significantly positively correlated with socialization and its two dimensions: general and specific of students and significant at $p$ value of 0.01 .

Linear regression analysis

Regression analysis was measured by testing the research hypotheses. The results for each variable are presented in below given tables.

\section{$\mathrm{H}_{1}$ : There is a relationship between social taboos and socialization}

Table 2: Analysis of correlation between social taboos and socialization of students

\begin{tabular}{|c|c|c|c|c|c|}
\hline Variables & R square & t-value & Coefficient & F-value & P value \\
\hline Social taboos & -0.685 & 13.52 & -0.67 & 269.0 & 0.00 \\
\hline
\end{tabular}

Table 2 shows the value of coefficient beta is calculated as -0.67 which shows a significantly negative relationship between social taboos and socialization. The value of R-square is calculated as -0.685 showing $68.5 \%$ variations in the dependant variable (social taboos) are explained by independent variable (socialization). The model's goodness of fit is shown by F-value that is 269.0 . Hence, $\mathrm{H}_{1}$ was accepted and it is proved that there is a significant negative correlation between social taboos and socialization of students.

\section{$\mathrm{H}_{2}$ : There is a relationship between social taboo and general socialization}

Table 3: Analysis of correlation between social taboos and socialization of students

\begin{tabular}{|c|c|c|c|c|c|}
\hline Variables & R square & t-value & Coefficient & F-value & P value \\
\hline Social taboos & -0.821 & 14.22 & -0.66 & 277.0 & 0.00 \\
\hline
\end{tabular}

Table 3 shows the value of coefficient beta is calculated as -0.66 which shows a significantly negative relationship between social taboos and general socialization. The value of $\mathrm{R}$-square is calculated as -0.821 showing $82.1 \%$ variation in the dependant variable (general socialization) is explained by independent variable (social taboos). The model's goodness of fit is shown by F-value that is 277.0. Hence, $\mathrm{H}_{2}$ was accepted and it is proved that there is a significant negative correlation between social taboos and general socialization of students.

$\mathrm{H}_{3}$ : There is a relationship between social taboo and specific socialization 
Table 4: Analysis of correlation between social taboos and socialization of students

\begin{tabular}{|c|c|c|c|c|c|}
\hline Variables & R square & t-value & Coefficient & F-value & P value \\
\hline Social taboos & -0.731 & 14.21 & -0.65 & 257.0 & 0.00 \\
\hline
\end{tabular}

Table 4 shows the value of coefficient beta is calculated as -0.65 which shows a significantly negative relationship between social taboos and specific socialization. The value of R-square is calculated as -0.731 showing $73.1 \%$ variation in the dependant variable (specific socialization) is explained by independent variable (social taboos). The model's goodness of fit is shown by F-value that is 257.0 . Hence, $\mathrm{H}_{2}$ was accepted and it is proved that there is a strong negative correlation between social taboos and specific socialization of students.

\section{Conclusion}

The paper investigated the effect of social taboos on socialization and its two dimensions: general socialization and specific socialization of students in secondary schools at Malakand division KPK, Pakistan. The correlation analysis showed a strong negative correlation between social taboos and socialization and the two dimensions of socialization: general and specific. The results of the study showed a strong negative direction in the relationship between the social taboos and socialization and the two dimensions of socialization.

On the basis of the findings, this study makes several conclusions. First, the study concludes that social taboos are important ingredient of the social norms and are protected by the cultural and customary sanctions which enable the individuals to get accustomed to these and learn to live in a society. Second, the results of this study also support the results of previous studies that social taboos are essential components of the societal patterns which shape the personality development of an individual in a particular society (Uzma, 2008; Qanbar, 2011). Third, the study also concludes that social taboos in a particular society are specifically protected and sanctioned by cultural mores, customary rules or by legal or religious injunctions. Last but not least, the study concludes that the results of this study further strengthen the findings of previous studies that in typical Pakistani society, some of the social taboos as discussed in the above literature are legally as well as morally sanctioned. This situation motivates the young people during the education to adapt to them with or without personal desires (Uzma, 2008; Khan, 2000).

\section{Recommendation for Future Research}

First, this study used a cross-sectional design for which data were collected one time during the study from a specific geographical area with a small sample. Second, the results may not be more reliable. Therefore, it is recommended that future research should use longitudinal method. This may produce more reliable and strong results. Third, Pakistani is a multi-cultural and multi-racial society. It does not reflect the truth related to the prevalence of social taboos in other parts of the country. Therefore, future studies may be conducted in other provinces of Pakistan to have more comprehensive view of the phenomenon.

\section{References}

Ali, T. S., Ali, P. A., Waheed, H., \& Memon, A. A. (2006). Understanding of puberty and related health problems among female adolescents in Karachi, Pakistan. Journal-Pakistan Medical Association, 56(2), 68-72.

Ahmad, K., Ghani, M., Alam, M., \& Gul, T. (2013). A sociolinguistic study of the linguistic taboos in the pashtoon society. International Researchers, 2(1), 36-41.

Al-Khatib, M. (1995). Sociolinguistic view of linguistic taboo in Jordanian Arabic. Journal of Multilingual and Multicultural Development, 16(6), $443-457$.

Bénabou, R., \& Tirole, J. (2004). Will power and personal rules. Journal of Political Economy, 112(4), 848-886.

Best, J. W., \& Kahn, V. K. (2005). Research in education (10th ed.). New Delhi: Pearson.

Colding, J., \& Folke, C. (2001). Social taboos: invisible systems of local resource management and biological conservation. Ecological Applications, 11(2), 584-600.

Cohen, L., Manion, L., \& Morrison, K. (2007). Observation: Research methods in education (6 $6^{\text {th }}$ ed.). Madison Avenue, NY: Routledge.

Durrant, V. (2000). Adolescent girls and boys in Pakistan: Opportunities and constraints in the transition to adulthood. Research Report No 12. Population Council: Islamabad, Pakistan.

Fehr, E., \& Fischbacher, U. (2004). Social norms and human cooperation. Trends in Cognitive Sciences, 8(4), 185-190.

Fershtmen, C., Gneezy, U., \& Hoffman, M. (2011). Taboos and identity: Considering the unthinkable. American Economic Journal: Microeconomics 3 (May 2011), 139-164. 
Fessler, D. M. T., \& Navarrette, C., D. (2003). Meat is good to taboo: Dietary proscriptions as a product of the interaction of psychological mechanisms and social processes. Journal of Cognition and Culture, 3(1), 1-40.

Fiske, A. P., \& Tetlock, P. E. (1997). Taboo trade-offs: Reactions to transactions that transgress the spheres of justice. Political Psychology, 18(2), 255-297.

Freud, S. (1955). Totem and taboo: Some points of agreement between the mental lives of savages and neurotics. In J. Strachey (Ed. and Trans.), The standard edition of the complete psychological works of Sigmund Freud (Vol. 13, pp. vii-162). London, UK: Hogarth Press.

Gay, L. R., Mills, G., \& Airasian, P. (2009). Educational research: Competencies for analysis and applications (9th ed.). Upper Saddle River, NJ: Pearson.

Government of Pakistan (2001). 1998 Census report of Pakistan. Population census organization statistics division, Islamabad, Pakistan.

Hussain, R., \& Khan, A. (2008). Women's perceptions and experiences of sexual violence in marital relationships and its effect on reproductive health. Health Care for Women International, 29(5), 468-483.

Holmes, J. (1992). An introduction to sociolinguistics. London: Longman.

Jejeebhoy, S., Shah, I., \& Puri, C. (Eds.). (2003). Towards adulthood: exploring the sexual and reproductive health of adolescents in South Asia. World Health Organization.

Khan, A. (1998). Female mobility and access to health and family planning services. A qualitative research study in three Punjabi villages. Islamabad: Ministry for Population Welfare.

Khan, A. (2000). Adolescents and reproductive health in Pakistan: A literature review. Research Report No. 11. Islamabad: Population Council.

Krejcie, R. V., \& Morgan, D. W. (1970). Determining sample size for research activities. Educational \& Psychological Measurement, 30, 607-610.

Mbaya, M. (2002). Linguistic taboo in African marriage context: A study of the Oromo Laguu Nordic. Journal of African Studies, 11(2), 224-235.

McCauley, A. P., Salter, C., Kiragu, K., \& Senderowitz, J. (1995). Meeting the needs of young adults. Population Reports Journal, 41(October), 1-43.

Qanbar, N. (2011). A sociolinguistic study of the linguistic taboos in the Yemeni. MJAL, 3(2), 86-104.

Seifried, B. (2006). Taboo: Cultural phenomenon headed for extinction? M.A Dissertation, Georgia State University.

Strong, A. K. (2005). Incest laws and absent taboos in Roman Egypt. Ancient History Bulletin, 19(1-2), 31-41.

Xiaoqin, G. (2001). Different Cultural Projections from Similar Verbal Taboos in English and Chinese. Foreign Languages and Their Teaching, 2, 010.

Young, H. P. (2011). The dynamics of social innovation. Proceedings of the National Academy of Sciences, 108(Supplement 4), $21285-$ 21291.

Zelizer, V. A. (1981). The price and value of children: The case of children's insurance. American Journal of Sociology, 86(5), 10361056.

Zia, A. (2012). Representation of women in Ali's twilight in Delhi (1940). International Journal of Research in Linguistics \& Lexicography, $1(4), 49-55$. 